\title{
Patient Discharge Instructions in the Emergency Department and Their Effects on Comprehension and Recall of Discharge Instructions: A Systematic Review and Meta-analysis
}

\author{
Amber E. Hoek, MD*; Susanne C. P. Anker, MD; Ed F. van Beeck, MD, PhD; Alex Burdorf, PhD; Pleunie P. M. Rood, MD, PhD; \\ Juanita A. Haagsma, PhD \\ *Corresponding Author. E-mail: a.e.hoek@erasmusmc.nl, Twitter: @HoekAmber.
}

\begin{abstract}
Study objective: We conduct a systematic review with meta-analysis to provide an overview of the different manners of providing discharge instructions in the emergency department (ED) and to assess their effects on comprehension and recall of the 4 domains of discharge instructions: diagnosis, treatment, follow-up, and return instructions.
\end{abstract}

\begin{abstract}
Methods: We performed a systematic search in the PubMed, EMBASE, Web of Science Google Scholar, and Cochrane databases for studies published before March 15, 2018. A quality assessment of included articles was performed. Pooled proportions of correct recall by manner of providing discharge instructions were calculated.
\end{abstract}

Results: A total of 1,842 articles were screened, and after selection, 51 articles were included. Of the 51 included studies, 12 used verbal discharge instructions only, 30 used written discharge instructions, and 7 used video. Correct recall of verbal, written, and video discharge instructions ranged from $8 \%$ to $94 \%, 23 \%$ to $92 \%$, and $54 \%$ to $89 \%$, respectively. Meta-analysis was performed on data of 1,460 patients who received verbal information only, 3,395 patients who received written information, and 459 patients who received video information. Pooled data showed differences in correct recall, with, on average, $47 \%$ for patients who received verbal information (95\% confidence interval $32.2 \%$ to $61.7 \%$ ), 58\% for patients who received written information (95\% confidence interval $44.2 \%$ to $71.2 \%$ ), and $67 \%$ for patients who received video information (95\% confidence interval $57.9 \%$ to $75.7 \%)$.

Conclusion: Communicating discharge instructions verbally to patients in the ED may not be sufficient. Although overall correct recall was not significantly higher, adding video or written information to discharge instructions showed promising results for ED patients. [Ann Emerg Med. 2019; $: 1-10$.

Please see page XX for the Editor's Capsule Summary of this article.

\section{INTRODUCTION}

To ensure that patients are discharged safely, it is important that they have a good understanding of their diagnosis, treatment, follow-up, and return instructions. Therefore, giving patient discharge instructions is an important task of health care professionals in the emergency department (ED).

In a planned and structured situation, such as an outpatient clinic, patient education may already be challenging. In the $\mathrm{ED}$, patient education is even more difficult because of multiple factors.

First, a visit to the ED is mostly an unplanned, unexpected, and therefore stressful situation for the patient. Frequently, patients have acute onset of pain and are worried about their health, which makes it difficult to focus on the provided information. Second, the ED can be crowded and hectic, with a high workload for the health care professionals. Patient instructions, frequently consisting of new and complex information, are often briefly explained and can therefore be difficult for patients to remember or reproduce. ${ }^{1}$ Third, patientrelated factors, such as a language barrier, impaired cognitive function, or low literacy, can complicate patient education. ${ }^{2}$ Fourth, disease-specific symptoms can also impede recall; for example, in patients with mild traumatic brain injury. ${ }^{3}$ 


\section{Editor's Capsule Summary}

What is already known on this topic

Patients discharged from the emergency department (ED) need a clear understanding of their home care and follow-up plans.

What question this study addressed

This systematic review examined whether there are differences in comprehension of verbal, verbal plus written, and verbal plus video discharge instructions.

What this study adds to our knowledge

Results for individual studies were highly variable. Video instructions produced the highest recall $(66.8 \%)$; however, they were not statistically better than written $(57.8 \%)$ or verbal-only $(47.0 \%)$ instructions.

\section{How this is relevant to clinical practice}

Patients may require a multimodal approach to receiving ED discharge instructions. Video may be useful in some cases.

Multiple studies have shown deficits in comprehension of discharge instruction. ${ }^{4-6}$ For example, Engel et $\mathrm{al}^{6}$ showed that a mere $13 \%$ of patients understood each of the 4 major domains of discharge instructions (diagnosis and cause, care given in the $\mathrm{ED}$, care after the $\mathrm{ED}$ visit, and instructions on when to return to the ED).

Various studies have investigated patient education with a range of communication tools, and their results suggest that type of communication may influence correct recall of patients. To better understand and quantify the differences in patients' comprehension of discharge information, a literature synthesis is needed. Our primary objective was to perform a systematic review with meta-analysis to provide an overview of the different manners of providing discharge instructions in the ED and to assess their effects on comprehension and recall of diagnosis, treatment, followup, and return instructions.

\section{MATERIALS AND METHODS}

\section{Study Design}

We conducted a systematic review following the Preferred Reporting Items for Systematic Reviews and Meta-analyses guidelines. ${ }^{7}$ We registered the design of this systematic review in the International Prospective Register of Systematic Reviews. ${ }^{8}$

\section{Selection of Participants and Data Collection and Processing}

We performed a systematic search in the PubMed, EMBASE, Web of Science Google Scholar, and Cochrane databases. The information specialist from the Academic Library of the Erasmus Medical Center Rotterdam assisted in developing an extensive literature search. The search terms are listed in Appendix E1 (available online at http:// www.annemergmed.com). Articles about discharge instructions in the ED that measured recall were included independently of patient characteristics. We included randomized controlled trials, retrospective and prospective cohort studies, cross-sectional studies, and time-series studies published before March 15, 2018. Articles not written in English were excluded.

Articles were first selected according to title and abstract by 2 independent reviewers (A.E.H. and S.C.P.A.). Then, final selection was made on articles' full text. In case of disagreement, a third researcher (J.A.H.) decided whether to include or exclude the debated article. References from selected articles were checked for relevant articles. For each included study, we extracted information on the participants (number, age, sex, education level, and language barrier), manner of patient education (verbal, written, video, telephone, or all 4), way of measuring correct recall, percentage of correct recall, and domain of patient education in which correct recall was measured.

The checklist of the Cochrane Library was used to assess the quality and risk of bias of each included article. Articles were judged on selection bias, performance bias, detection bias, attrition bias, and reporting bias, and a conclusion was made about overall risk of bias for each article.?

\section{Outcome Measures}

The outcome measure of our study was comprehension and recall of discharge instructions after the ED visit. Discharge instructions were subdivided into 4 domains: diagnosis, prognosis, treatment, and return instructions. Comprehension and recall of discharge instructions were determined by manner of providing discharge instruction.

\section{Primary Data Analysis}

Manner of providing discharge instructions (information on diagnosis, treatment, follow-up, return instructions, or all 4) was categorized into verbal, written, video, and telephone discharge instructions. For each of these categories, pooled correct recall was determined, expressed by percentage of patients who could correctly recall discharge instructions. We followed a step-by-step guide to perform a meta-analysis by manner of providing discharge 
instructions, using a random-effects model in an Excel spreadsheet (version 2010; Microsoft, Redmond, WA). ${ }^{10}$ We used spreadsheets capable of producing customized forest plots that were developed by Neyeloff et $\mathrm{al}^{10}$ to generate the forest plots. Studies that reported only increase of correct recall or studies that did not report overall proportions of correct recall were excluded from the calculation of pooled estimates of correct recall. A metaanalysis was not conducted for discharge instructions by telephone because only 2 studies were available.

We used the $I^{2}$ statistic to assess the percentage of variation across studies that is due to heterogeneity rather than chance. ${ }^{11}$ An $I^{2}$ value of $25 \%$ or lower is associated with low heterogeneity, $50 \%$ is associated with moderate heterogeneity, and $75 \%$ or higher is associated with high heterogeneity. ${ }^{11}$ Subsequently, we compared the pooled correct recall and confidence intervals (CIs) of verbal, written, and video discharge instructions. We used CIs to assess whether correct recall by manner of providing discharge instructions was statistically significant.

\section{RESULTS}

The search resulted in 1,842 articles; after selection, 51 met the inclusion and exclusion criteria (Figure 1). Of the 51 included studies, 12 used verbal discharge instructions only, ${ }^{12-23} 30$ used written discharge instructions, ${ }^{3,5,6,24-51}$ 7 used video, ${ }^{52-58}$ and 2 used telephone ${ }^{59,60}$ discharge
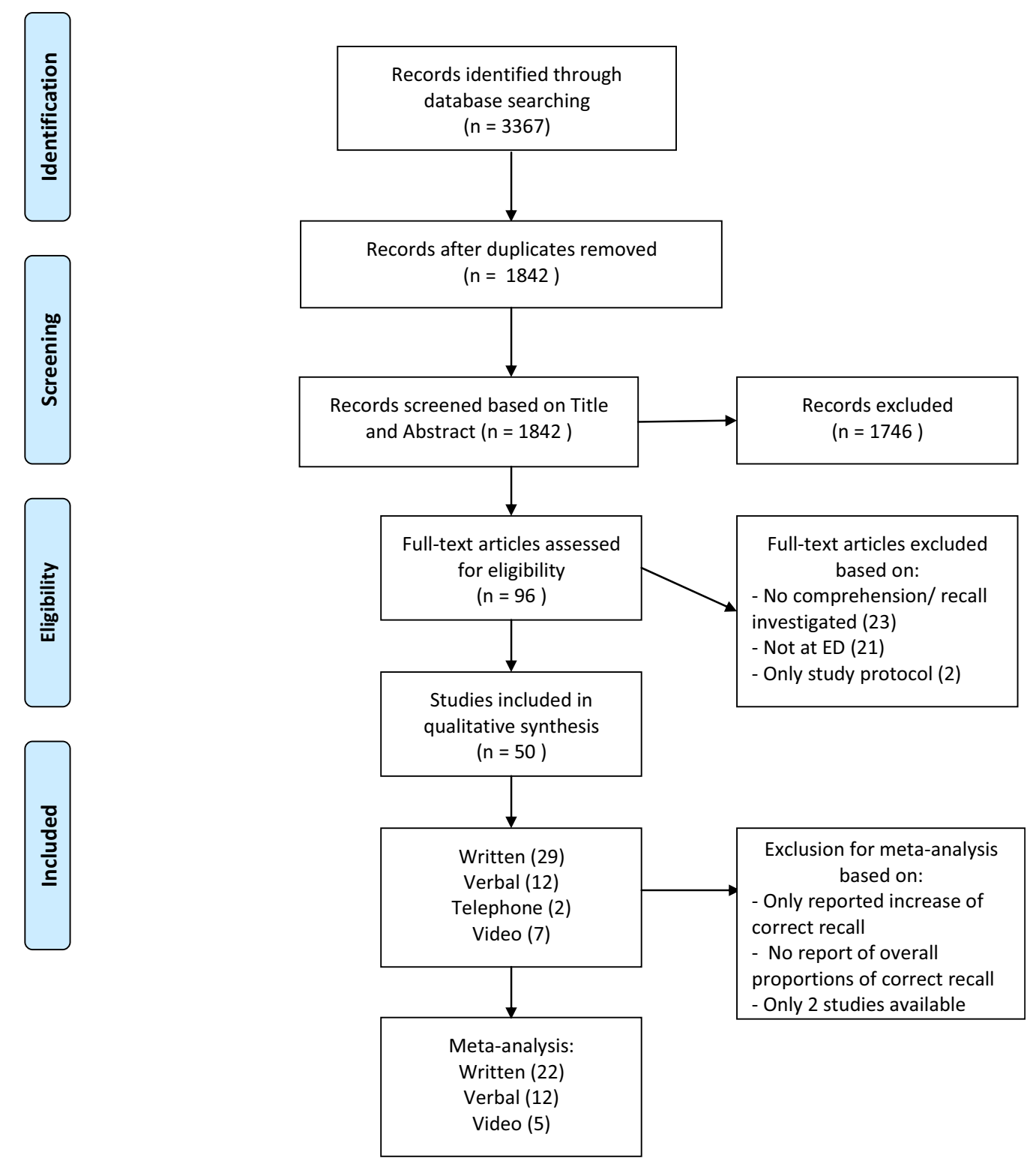

Figure 1. Flowchart of the study identification process. 
instructions. Of these, 33 were observational cross-sectional studies and 18 were randomized controlled trials.

The quality assessment of the included studies is shown in Appendix E2 (available online at http://www.

annemergmed.com). We assessed articles according to their way of generating comparable groups and found several randomized controlled trials ${ }^{24,47,54,56,57}$ and 62 -phase cohort trials $^{3,22,35,48,51,58}$ to have a high risk of bias.

Because of a significant percentage of patients lost to follow-up, we judged 14 articles $3,15,21,25,30,34,37,44-$

$46,52,54,58,59$ to have a high risk of incomplete data. Twenty articles did not describe the level of education ${ }^{6,15,17,20-22,24 \text {, }}$ 27,29,35,39,44,46,48,52,53,55,58-60 and 9 articles did not mention whether there was a language barrier ${ }^{12,15,23,25,35,43,44,51,60}$ and therefore probably had selection bias.

Most studies assessed recall of discharge instructions in 4 domains: diagnosis, treatment, follow-up instructions, and return instructions. Recall was measured in different ways throughout the different studies; for example, by face-toface interview, telephone interview, or written questionnaire.

All patients discharged from the ED normally receive verbal discharge instructions. We found 12 studies that investigated recall of verbal discharge instructions. In these studies, correct recall of such instructions differed widely, from $8 \%$ to $94 \%$ (Table 1 in Appendix E2, available online at http://www.annemergmed.com). ${ }^{12-23}$

In various studies, one or more of the different domains of patient education were investigated. For example, a single-center cross-sectional study demonstrated that $66 \%$ of patients had a fair or poor understanding of discharge instructions in at least one domain of discharge instructions. ${ }^{16}$ Another cross-sectional study found that the most accurate recall was on domain of diagnosis; this was correct for $82 \%$ of patients, whereas only $43 \%$ of patients could correctly recall discharge instructions in all 4 domains. ${ }^{15}$ Complete understanding of their diagnosis was reported for only half of the patients. ${ }^{18}$

In a study that specifically investigated knowledge of prescribed medication by questionnaire, none of the questions were answered correctly by $37 \%$ of patients. Fifty-seven percent of patients could recall the purpose of the medication, and $62 \%$ could recall when to receive the medication. Only $8 \%$ of patients could answer all questions on medication use correctly. ${ }^{12}$

In regard to follow-up instructions, of all adult patients in the study by Qureshi et al, ${ }^{17} 94 \%$ who were advised to consult their general practitioner after their ED visit could recall this advice correctly.

In general, there seems to be no correlation between the number of domains measured in the different studies and correct recall. Studies investigating 4 domains showed correct recall for $19.9 \%$ to $67 \%$ of patients. ${ }^{14,20}$ Studies investigating only one domain showed correct recall for $25.3 \%$ to $94 \%$ of patients. ${ }^{12,17}$ However, according to one study, recall seemed better if just one simple instruction was given to a patient. ${ }^{17}$

Griffey et $\mathrm{al}^{13}$ studied a special conversation technique used with verbal instructions, the teach-back method whereby a patient is asked to "teach back" the information received from a caregiver to receive clarifying feedback from him or her. They found a significant improvement in comprehension of follow-up instructions of $31 \%$, but no significant difference in comprehension of diagnosis and treatment. However, a more recent prospective before-after study found that the teach-back method had an improvement of recall of $15 \%$ in all aspects of discharge instructions, regardless of patient age and education level. ${ }^{19}$

One study showed that if verbal instructions were supported by illustrations on a tablet, understanding of diagnosis and treatment improved significantly. ${ }^{14}$

Four studies specifically investigated verbal discharge instructions for parents of children discharged from the ED. Waisman et $\mathrm{al}^{23}$ found correct recall of discharge instructions for $75 \%$ of parents. However, Chappuy et $\mathrm{al}^{20}$ found that only $20 \%$ of parents understood all domains of discharge instructions correctly, and recall was less when parents thought their child was in pain. Two studies found that verbal instructions improved recall significantly if added to written discharge instructions. ${ }^{21,22}$

Twenty-nine studies investigated recall of written discharge instructions. Most studies showed that adding verbal instructions improved correct recall of discharge instructions significantly, with $7 \%$ to $31 \%$ correct recall (Table 2 in Appendix E2, available online at http://www. annemergmed.com). 5,25,26,33,34 Nonetheless, several studies showed a wide range of incorrect recall in at least one domain, varying from $23 \%$ to $92 \%$. $6,27,29,32,37,39$

Four studies specifically investigated elderly patients. ${ }^{41,43-45}$ For example, Hastings et $\mathrm{al}^{43,44}$ found that $43 \%$ to $56 \%$ of patients did not understand return instructions completely. They found improvement on recall of medication knowledge if written instructions were individualized instead of preprinted in a standard format. ${ }^{45}$ Even with written discharge instructions, patients with cognitive impairment were less likely to correctly recall the discharge instructions than those without cognitive impairment. ${ }^{41}$

To improve patients' recall, written discharge instructions could be optimized. A randomized controlled trial that compared written instructions with and without illustrations showed that adding illustrations improved 
correct recall significantly. ${ }^{24,28}$ If written information is simplified, correct recall improves significantly. ${ }^{30,38}$

Another factor influencing correct recall of written discharge instruction is health literacy. Patients with a low health literacy had less understanding of discharge instructions than those with high literacy. ${ }^{36}$

Studies investigating parents of children discharged from the ED with written instructions found that when verbal and written information was combined, correct recall was better than when verbal-only or written-only information was used, ${ }^{3,47,48}$ especially for treatment discharge instructions. ${ }^{51}$ Although $93 \%$ of parents thought they understood the discharge instructions about diagnoses for their child, there was incorrect recall for $22 \%$ of parents. ${ }^{49}$ Another study found 32\% incorrect recall about treatment of the child even after parents received written discharge instructions. ${ }^{50}$ A study using storytelling (written experiences from other parents) as a communication tool showed no difference in correct recall. ${ }^{42}$

Seven studies investigated recall of video discharge instructions. Discharge instructions using an information video improved recall significantly (Table 3 in Appendix E2, available online at http://www.annemergmed. com). ${ }^{52,54}$ Nonetheless, these studies showed a wide range of correct recall in at least one domain, varying from $54 \%$ to $89 \%$. For example, Chakravarthy et $\mathrm{al}^{53}$ showed improvement from $65 \%$ to $82 \%$ correct recall when a discharge video was used.
Most studies using a video were targeted at parents of children discharged from the ED. The parents showed significant improvement in knowledge of the diagnosis and treatment compared with those who did not see the information video. ${ }^{55-58}$

Two studies investigated recall of discharge instructions by telephone. These studies showed that adding telephone follow-up to standard discharge instructions did not improve correct recall in elderly patients and parents (Table 4 in Appendix E2, available online at http://www. annemergmed.com). ${ }^{60,61}$

A meta-analysis was performed on data of 1,460 patients who received verbal information only, 3,395 patients who received written information, and 459 patients who received video information. Figures 2 to 4 provide an overview of the overall pooled correct recall of verbal, written, and video discharge instruction. Variation in correct recall was moderate across studies on video discharge instructions $\left(I^{2}=50.1 \%\right)$ and high across those on verbal and written discharge instructions (verbal $I^{2}=95.6 \%$; written $I^{2}=97.7 \%$ ). The highest pooled recall was estimated for video discharge instructions (number of studies $=6$; pooled correct recall $66.8 \%$; $95 \%$ CI $57.9 \%$ to $75.7 \%$ ) and written discharge instructions (number of studies=22; pooled correct recall $57.8 \%$; $95 \%$ CI $44.2 \%$ to $71.2 \%)$. The pooled correct recall of verbal discharge instructions was $47.0 \%$ (number of studies $=11 ; 95 \% \mathrm{CI}$ $32.2 \%$ to $61.7 \%)$.

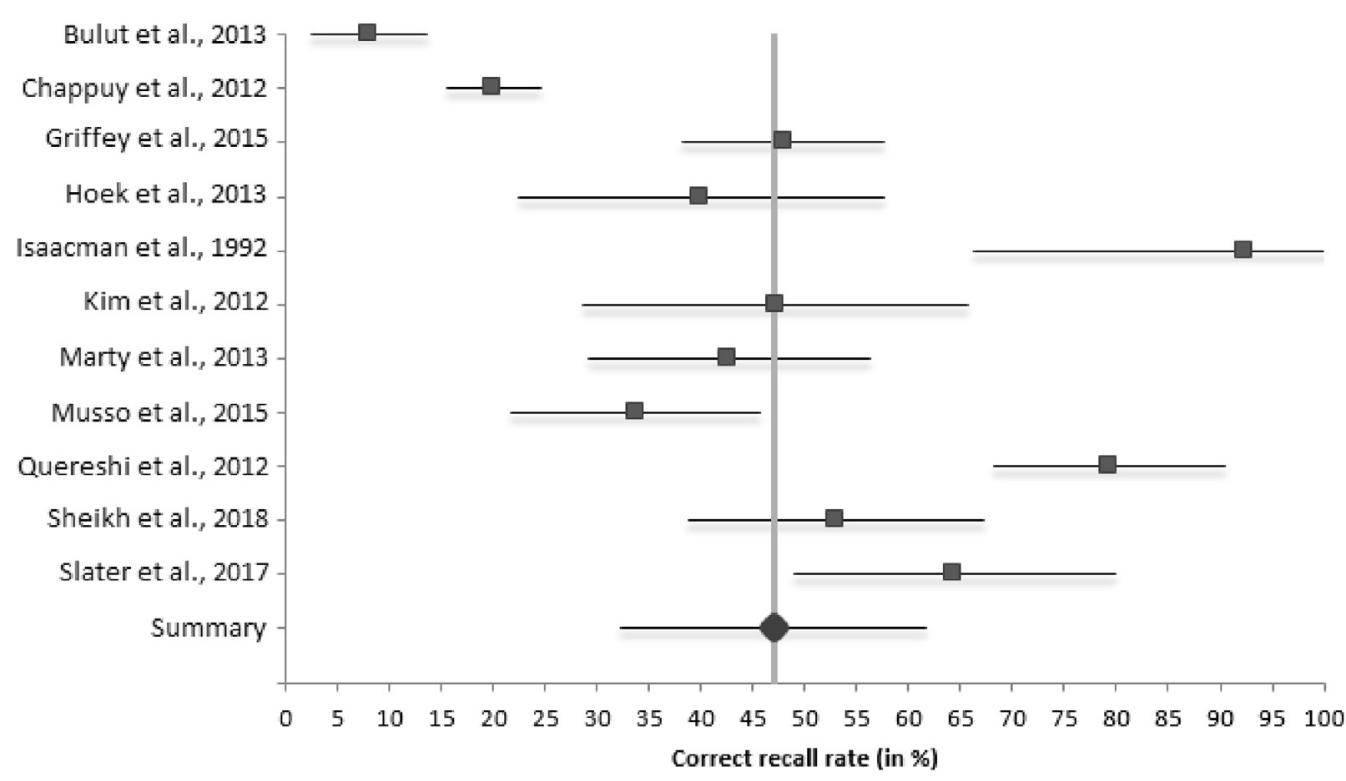

Figure 2. Forest plot of pooled correct recall rates of verbal discharge instruction. 


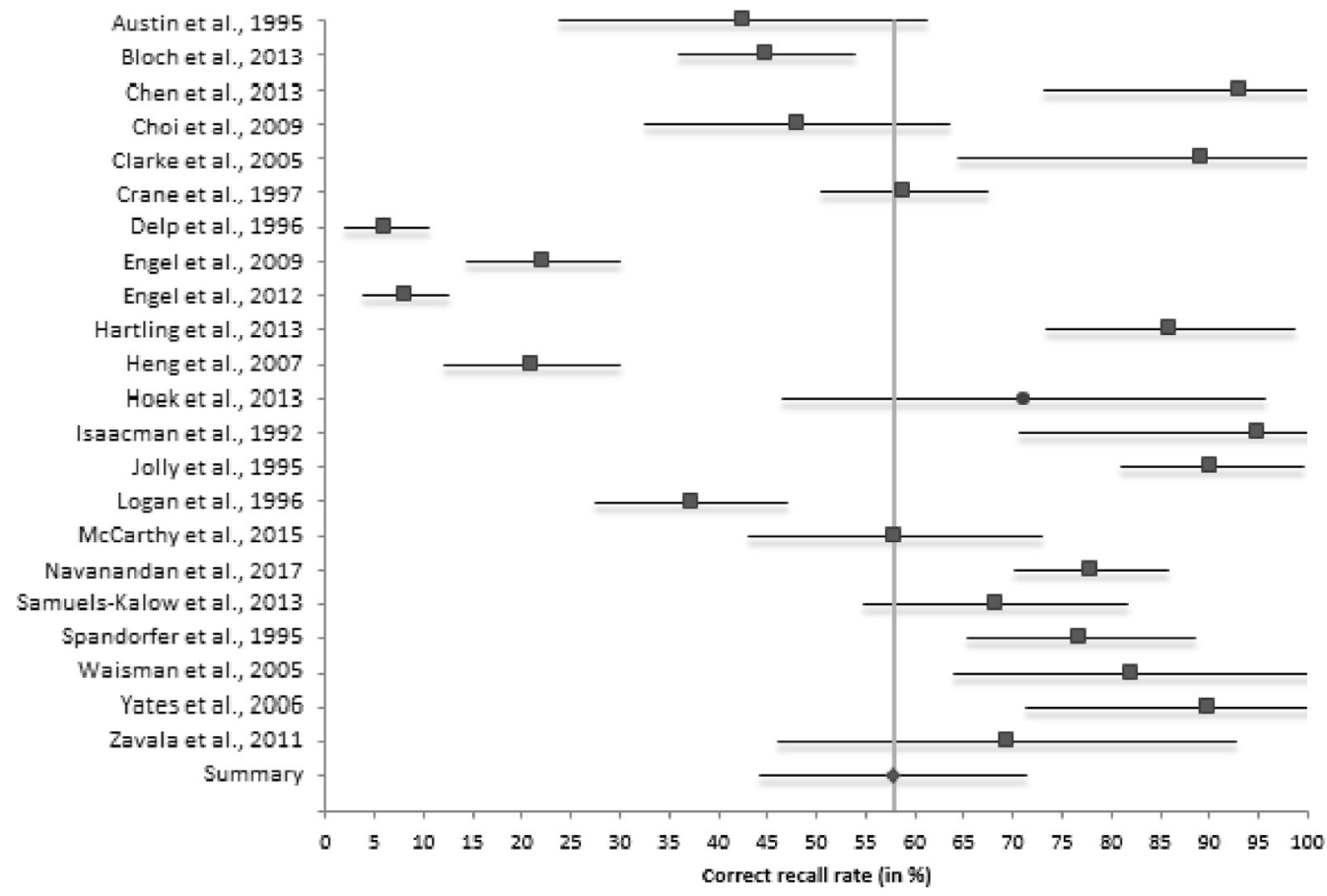

Figure 3. Forest plot of pooled correct recall rates of written discharge instruction.

\section{LIMITATIONS}

This systematic review has several limitations. First, the included studies are difficult to compare because of the variety in methods for discharge instructions, different ways of measuring and different definitions of recall, and heterogeneity in patient populations. For example, studies have used different follow-up periods to measure recall. It has been shown that duration between providing discharge instructions and measuring recall influences outcome. ${ }^{62}$ This might influence the results of the meta-analysis, although the ED patient population is heterogeneous and patients must receive discharge instructions based on the best available evidence.

Second, not all included studies were of the same quality; nevertheless, in the group of verbal, written, and video discharge instructions there were enough articles of relatively good quality to draw conclusions.

Third, our review focused on correct recall of diagnosis, treatment, follow-up, and return instructions. We did not investigate whether correct recall influences patients'

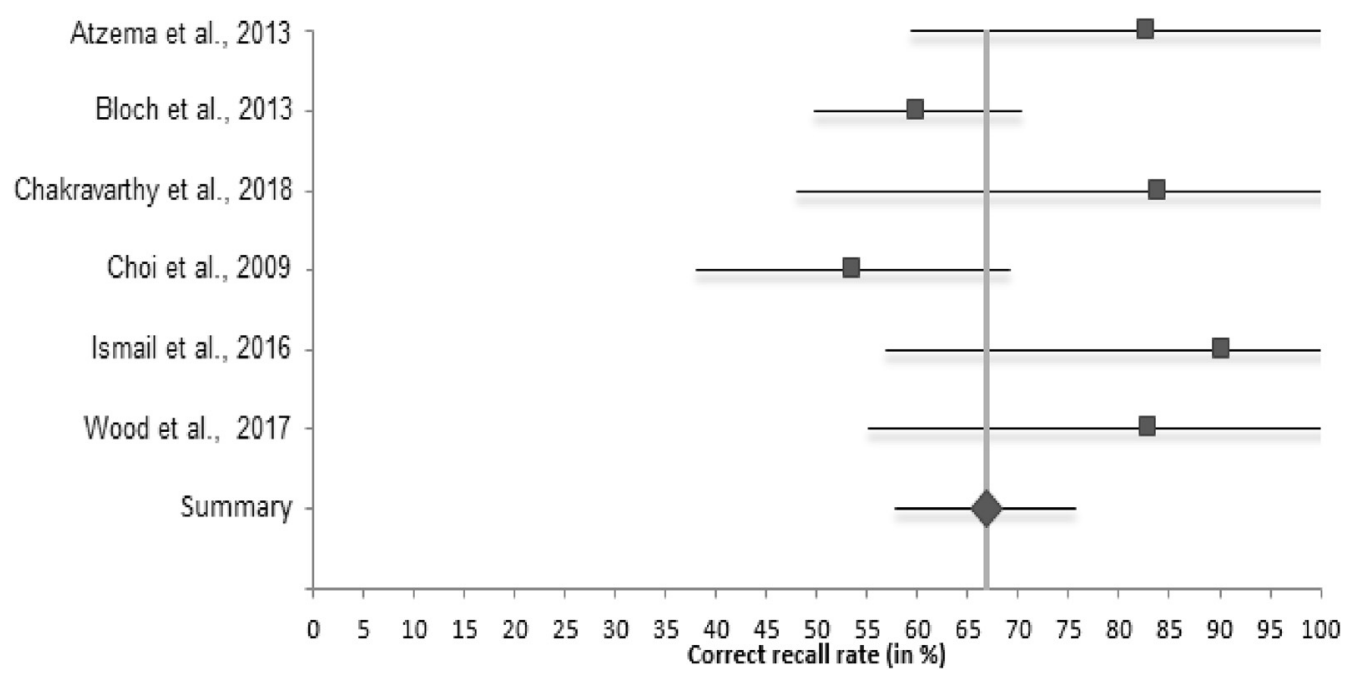

Figure 4. Forest plot of pooled correct recall rates of video discharge instruction. 
symptoms, recovery, or both. For future studies, we recommend studying the health benefits of correct recall of discharge instructions in the ED.

Fourth, we categorized the included articles in the manner of discharge instructions (verbal, written, video, or telephone); however, discharge instructions are seldom provided in isolation. Although not measured in all the studies, the effect of verbal discharge instructions might influence the other manners of discharge instructions.

\section{DISCUSSION}

To our knowledge, this is the first systematic review with a meta-analysis about discharge instructions and their effect on correct recall in the ED. We distinguished 4 types of discharge instructions: verbal only, written information, video, and telephone follow-up. It is essential to differentiate between those types to determine the optimal way to provide discharge instructions so ED patients can be discharged home safely.

Verbal discharge instructions are part of standard care, although the results of our review showed that correct recall with this manner could be as low as $8 \%$. Training of providers of discharge instructions on communication with the teach-back method might improve recall.

Our findings suggest that adding written information to standard care could improve recall from $47 \%$ to $58 \%$ on average. This result is comparable to those of studies in other research fields; for example, in rheumatic patients who received colchicine treatment and for patients who underwent cataract or hip surgery. ${ }^{63-65}$

The overall correct recall of adding a video to the discharge instructions was, although not significant, higher than correct recall in patients who received written instructions. All individual studies showed improvement of recall compared with standard care, with or without written information. This is comparable to other results found in different patient populations. ${ }^{66,67}$

Although there seems to be a trend toward adding video to discharge instructions as the optimal manner, our metaanalysis showed that recall did not significantly improve. However, comparison between video and written information is hampered by the fact that videos were often used to inform about more complicated topics. For example, information about follow-up appointment after the ED visit is easier to remember than information about diagnosis and treatment. ${ }^{17,56}$ In other fields of medicine, patient education with video shows promising results. For example, a study directed to pregnant women that investigated patient education on influenza vaccination showed that women who were shown an instruction video in addition to verbal information had significantly better understanding of the information about influenza vaccination compared with women who received only verbal information from a physician. ${ }^{67}$ Furthermore, a study on patients with atrial fibrillation showed significant improvement of knowledge of atrial fibrillation when a video was added to verbal instructions compared with verbal instructions only. ${ }^{68}$ More research is needed to investigate recall of video discharge instructions on the ED population, particularly in specific patient populations, such as patients with low health literacy. A study among patients with low health literacy showed a significantly better understanding of information about screening for colorectal cancer when animations combined with spoken text were used compared with written text only. ${ }^{66}$

Moreover, the health benefit of correct recall of discharge instructions needs further investigation.

Heterogeneity in patient-population-related and patientrelated factors, such as low health literacy or language barrier, may have contributed to the wide variation in correct recall by manner of discharge instructions. A study with volunteers from an outpatient clinic showed that health literacy might negatively influence understanding and recall of discharge instructions. ${ }^{2}$ Because there were only a few articles reporting the effect of health literacy in the ED, we were not able to draw conclusions about the effect of health literacy on correct recall of discharge instructions. A language barrier might prohibit correct recall of discharge instructions. ${ }^{69}$ However, in most studies included in this review, a language barrier was an exclusion criterion for enrollment in the study, so we were not able to provide an overview of the effect of language barrier on ED discharge instructions.

Other factors influencing recall of information as described in other areas of medical education may also be present in different levels for each patient; for example, emotional state during education, preexisting health status, and amount of information. ${ }^{70}$ However, the included studies provided no information about these factors.

Communicating discharge instructions verbally to patients in the ED may not be sufficient. Although overall correct recall was not significantly higher, adding video or written information to discharge instructions showed promising results for ED patients. Further investigation is necessary to evaluate the effect of written and video discharge instructions on recall, including study of the health benefits of correct recall of discharge instructions in the ED.

The authors acknowledge Wichor M. Bramer, PhD, information specialist medical librararian, Erasmus Medical 


\section{Center Rotterdam, for his help with developing an extensive literature search.}

Supervising editor: Theodore R. Delbridge, MD, MPH. Specific detailed information about possible conflict of interest for individual editors is available at https://www.annemergmed.com/ editors.

Author affiliations: From the Department of Emergency Medicine (Hoek, Anker, Rood, Haagsma) and the Department of Public Health (van Beeck, Burdorf, Haagsma), Erasmus Medical Center Rotterdam, Rotterdam, the Netherlands.

Author contributions: AEH, EFvB, AB, PPMR, and JAH conceptualized the design of the study. AEH and SCPA wrote the study protocol with input from all authors, searched literature, selected the articles, and extracted data from them. JAH performed the meta-analysis. All authors interpreted the data and read and approved the final article. AEH, SCPA, and JAH drafted the article. $A B, E F v B$, and PPMR revised the article critically for important intellectual content. $X X$ takes responsibility for the paper as a whole.

All authors attest to meeting the four ICMJE.org authorship criteria: (1) Substantial contributions to the conception or design of the work; or the acquisition, analysis, or interpretation of data for the work; AND (2) Drafting the work or revising it critically for important intellectual content; AND (3) Final approval of the version to be published; AND (4) Agreement to be accountable for all aspects of the work in ensuring that questions related to the accuracy or integrity of any part of the work are appropriately investigated and resolved.

Funding and support: By Annals policy, all authors are required to disclose any and all commercial, financial, and other relationships in any way related to the subject of this article as per ICMJE conflict of interest guidelines (see www.icmje.org). The authors have stated that no such relationships exist.

Publication dates: Received for publication March 25, 2019. Revision received May 10, 2019. Accepted for publication June 10, 2019.

Trial registration number: CRD 42018093700

\section{REFERENCES}

1. Wilson EA, Wolf MS. Working memory and the design of health materials: a cognitive factors perspective. Patient Educ Couns. 2009; 74:318-322.

2. McCarthy DM, Waite KR, Curtis LM, et al. What did the doctor say? health literacy and recall of medical instructions. Med Care. 2012;50:277-282.

3. Al-Harthy N, Sudersanadas KM, Al-Mutairi M, et al. Efficacy of patient discharge instructions: a pointer toward caregiver friendly communication methods from pediatric emergency personnel. J Family Community Med. 2016;23:155-160.

4. Samuels-Kalow ME, Stack AM, Porter SC. Effective discharge communication in the emergency department. Ann Emerg Med. 2012;60:152-159.

5. Hoek AE, De Ridder MA, Bayliss A, et al. Effective strategy for improving instructions for analgesic use in the emergency department. Eur J Emerg Med. 2013;20:210-213.
6. Engel KG, Heisler M, Smith DM, et al. Patient comprehension of emergency department care and instructions: are patients aware of when they do not understand? Ann Emerg Med. 2009;53:454-461. e15.

7. Moher D, Liberati A, Tetzlaff J, et al. Preferred Reporting Items for Systematic Reviews and Meta-analyses: the PRISMA statement. PLoS Med. 2009;6:e1000097.

8. Booth A, Clarke M, Ghersi D, et al. An international registry of systematic-review protocols. Lancet. 2011;377:108-109.

9. Higgins JP, Altman DG, Gotzsche PC, et al. The Cochrane Collaboration's tool for assessing risk of bias in randomised trials. BMJ. 2011;343:d5928.

10. Neyeloff JL, Fuchs SC, Moreira LB. Meta-analyses and forest plots using a Microsoft Excel spreadsheet: step-by-step guide focusing on descriptive data analysis. BMC Res Notes. 2012;5:52.

11. Higgins JP, Thompson SG, Deeks JJ, et al. Measuring inconsistency in meta-analyses. BMJ. 2003;327:557-560.

12. Bulut H, Tanrikulu G, Dal T, et al. How much do ED patients know about medication prescribed for them on discharge? a pilot study in Turkey. $J$ Emerg Nurs. 2013;39:e27-e32.

13. Griffey RT, Shin N, Jones S, et al. The impact of teach-back on comprehension of discharge instructions and satisfaction among emergency patients with limited health literacy: a randomized, controlled study. J Commun Healthc. 2015;8:10-21.

14. Kim HK, Ahn JH, You JY, et al. The efficacy of discharge instructions provided by a tablet personal computer for aiding the comprehension and satisfaction of patients with ureteral stones. J Korean Soc Emerg Med. 2012;23:712-720.

15. Marty H, Bogenstätter Y, Franc G, et al. How well informed are patients when leaving the emergency department? comparing information provided and information retained. Emerg Med J. 2013;30:53-57.

16. Musso MW, Perret JN, Sanders T, et al. Patients' comprehension of their emergency department encounter: a pilot study using physician observers. Ann Emerg Med. 2015;65:151-155.e4.

17. Qureshi R, Asha SE, Zahra M, et al. Factors associated with failure to follow up with a general practitioner after discharge from the emergency department. Emerg Med Australas. 2012;24:604-609.

18. Sheikh H, Brezar A, Dzwonek A, et al. Patient understanding of discharge instructions in the emergency department: do different patients need different approaches? Int J Emerg Med. 2018;11:5.

19. Slater BA, Huang Y, Dalawari P. The impact of teach-back method on retention of key domains of emergency department discharge instructions. J Emerg Med. 2017;53:e59-e65.

20. Chappuy H, Taupin P, Dimet J, et al. Do parents understand the medical information provided in paediatric emergency departments? a prospective multicenter study. Acta Paediatr. 2012;101:1089-1094.

21. Patel B, Kennebeck SS, Caviness AC, et al. Use of a discharge facilitator improves recall of emergency department discharge instructions for acute gastroenteritis. Pediatr Emerg Care. 2009;25:558-564.

22. Thomas DG, Bradley L, Servi A, et al. Parental knowledge and recall of concussion discharge instructions. J Emerg Nurs. 2018;44:52-56.

23. Waisman $\mathrm{Y}$, Siegal N, Chemo M, et al. Do parents understand emergency department discharge instructions? a survey analysis. Isr Med Assoc J. 2003;5:567-570.

24. Austin PE, Matlack IR, Dunn KA, et al. Discharge instructions: do illustrations help our patients understand them? Ann Emerg Med. 1995;25:317-320.

25. Chen YC, Wang YC, Chen WK, et al. The effectiveness of a health education intervention on self-care of traumatic wounds. J Clin Nurs. 2013;22:2499-2508.

26. Clarke C, Friedman SM, Shi K, et al. Emergency department discharge instructions comprehension and compliance study. CJEM. 2005;7:5-11. 
27. Crane JA. Patient comprehension of doctor-patient communication on discharge from the emergency department. J Emerg Med. 1997:15:1-7.

28. Delp C, Jones J. Communicating information to patients: the use of cartoon illustrations to improve comprehension of instructions. Acad Emerg Med. 1996;3:264-270.

29. Engel KG, Buckley BA, Forth VE, et al. Patient understanding of emergency department discharge instructions: where are knowledge deficits greatest? Acad Emerg Med. 2012;19:1035-1044.

30. Jolly BT, Scott JL, Sanford SM. Simplification of emergency department discharge instructions improves patient comprehension. Ann Emerg Med. 1995;26:443-446.

31. Lin MJ, Tirosh AG, Landry A. Examining patient comprehension of emergency department discharge instructions: who says they understand when they do not? Intern Emerg Med. 2015;10:993-1002.

32. Logan PD, Schwab RA, Salomone IJA, et al. Patient understanding of emergency department discharge instructions. South Med J. 1996;89:770-774.

33. McCarthy DM, Wolf MS, McConnell R, et al. Improving patient knowledge and safe use of opioids: a randomized controlled trial. Acad Emerg Med. 2015;22:331-339.

34. Reis PGTA, Nakakogue C, Nakakogue T, et al. Guidelines for discharge: do standardized cards help in patient understanding? Rev Col Bras Cir. 2013;40:335-341.

35. Simmons S, Sharp B, Fowler J, et al. Mind the (knowledge) gap: the effect of a communication instrument on emergency department patients' comprehension of and satisfaction with care. Patient Educ Couns. 2015;98:257-262.

36. Smith PC, Brice JH, Lee J. The relationship between functional health literacy and adherence to emergency department discharge instructions among Spanish-speaking patients. J Natl Med Assoc. 2012:104:521-527.

37. Spandorfer JM, Karras DJ, Hughes LA, et al. Comprehension of discharge instructions by patients in an urban emergency department. Ann Emerg Med. 1995;25:71-74.

38. Yates K, Pena A. Comprehension of discharge information for minor head injury: a randomised controlled trial in New Zealand. N Z Med J 2006;119:U2101.

39. Zavala S, Shaffer C. Do patients understand discharge instructions? J Emerg Nurs. 2011;37:138-140.

40. Bell EJ, Takhar SS, Beloff JR, et al. Information technology improves emergency department patient discharge instructions completeness and performance on a national quality measure: a quasi-experimenta study. Appl Clin Informatics. 2013;4:499-514.

41. Han JH, Bryce SN, Ely EW, et al. The effect of cognitive impairment on the accuracy of the presenting complaint and discharge instruction comprehension in older emergency department patients. Ann Emerg Med. 2011:57:662-671.e2.

42. Hartling L, Scott SD, Johnson DW, et al. A randomized controlled tria of storytelling as a communication tool. PLoS One. 2013;8:e77800.

43. Hastings S, Stechuchak K, Oddone E, et al. Older veterans and emergency department discharge information. BMJ Qual Saf. 2012;21:835-842.

44. Hastings SN, Barrett A, Weinberger M, et al. Older patients' understanding of emergency department discharge information and its relationship with adverse outcomes. J Patient Saf. 2011;7:19-25.

45. Hayes KS. Randomized trial of geragogy-based medication instruction in the emergency department. Nurs Res. 1998;47:211-218.

46. Heng KWJ, Tham KY, How KY, et al. Recall of discharge advice given to patients with minor head injury presenting to a Singapore emergency department. Singapore Med J. 2007;48:1107-1110

47. Isaacman DJ, Purvis K, Gyuro J, et al. Standardized instructions: do they improve communication of discharge information from the emergency department? Pediatrics. 1992:89(6

suppl):1204-1208.

48. Kaestli LZ, Noble S, Combescure C, et al. Drug information leaflets improve parental knowledge of their child's treatment at paediatric emergency department discharge. Eur J Hosp Pharm Sci Pract. 2016;23:151-155.

49. Navanandan N, Schmidt SK, Cabrera N, et al. The caregiver perspective on unscheduled 72-hour return visits to pediatric acute care sites: a focus on discharge processes. Acad Pediatr. 2017;17:755-761.

50. Samuels-Kalow ME, Stack AM, Porter SC. Parental language and dosing errors after discharge from the pediatric emergency department. Pediatr Emerg Care. 2013;29:982-987.

51. Waisman Y, Siegal N, Siegal G, et al. Role of diagnosis-specific information sheets in parents' understanding of emergency department discharge instructions. Eur J Emerg Med. 2005;12:159-162.

52. Atzema CL, Austin PC, Wu L, et al. Speak fast, use jargon, and don't repeat yourself: a randomized trial assessing the effectiveness of online videos to supplement emergency department discharge instructions. PLoS One. 2013;8:e77057.

53. Chakravarthy B, Somasundaram S, Mogi J, et al. Randomized pilot trial measuring knowledge acquisition of opioid education in emergency department patients using a novel media platform. Subst Abus 2018;39:27-31.

54. Choi S, Ahn J, Lee D, et al. The effectiveness of mobile discharge instruction videos (MDIVs) in communicating discharge instructions to patients with lacerations or sprains. South Med J. 2009;102:239-247.

55. Baker MD, Monroe KW, King WD, et al. Effectiveness of fever education in a pediatric emergency department. Pediatr Emerg Care. 2009;25:565-568.

56. Bloch SA, Bloch AJ. Using video discharge instructions as an adjunct to standard written instructions improved caregivers' understanding of their child's emergency department visit, plan, and follow-up: a randomized controlled trial. Pediatr Emerg Care. 2013;29:699-704.

57. Ismail S, McIntosh M, Kalynych C, et al. Impact of video discharge instructions for pediatric fever and closed head injury from the emergency department. J Emerg Med. 2016;50:e177-e183.

58. Wood EB, Harrison G, Trickey A, et al. Evidence-based practice: videodischarge instructions in the pediatric emergency department. J Emerg Nurs. 2017;43:316-321.

59. Biese K, Lamantia M, Shofer F, et al. A randomized trial exploring the effect of a telephone call follow-up on care plan compliance among older adults discharged home from the emergency department. Acad Emerg Med. 2014;21:188-195.

60. Khan MSR, O'Meara M, Stevermuer TL, et al. Randomized controlled trial of asthma education after discharge from an emergency department. J Paediatr Child Health. 2004:40:674-677.

61. Biese KJ, Busby-Whitehead J, Cai J, et al. Telephone follow-up for older adults discharged to home from the emergency department: a pragmatic randomized controlled trial. J Am Geriatr Soc. 2018;66:452-458.

62. McGuire LC. Remembering what the doctor said: organization and adults' memory for medical information. Exp Aging Res. 1996;22:403-428.

63. Cinar Fl, Tosun N, Akbayrak N, et al. Comparison of the efficacy of written information vs verbal plus written information in rheumatic patients who receive colchicine treatment. Gulhane Med J. 2013;55:94-100.

64. Langdon IJ, Hardin R, Learmonth ID. Informed consent for total hip arthroplasty: does a written information sheet improve recall by patients? Ann R Coll Surg Engl. 2002;84:404-408. 
65. Shukla AN, Daly MK, Legutko P. Informed consent for cataract surgery: patient understanding of verbal, written, and videotaped information. J Cataract Refract Surg. 2012;38:80-84.

66. Meppelink CS, van Weert JC. The effectiveness of health animations in audiences with different health literacy levels: an experimental study. 2015;17:e11.

67. Goodman K, Mossad SB, Taksler GB, et al. Impact of video education on influenza vaccination in pregnancy. J Reprod Med. 2015;60:471-479.
68. Gagne M, Legault C, Boulet LP, et al. Impact of adding a video to patient education on quality of life among adults with atrial fibrillation: a randomized controlled trial. Patient Educ Couns. 2019;102:1490-1498.

69. Karliner LS, Auerbach A, Napoles A, et al. Language barriers and understanding of hospital discharge instructions. Med Care. 2012:50:283-289.

70. Watson PW, McKinstry B. A systematic review of interventions to improve recall of medical advice in healthcare consultations. $J R$ Soc Med. 2009;102:235-243. 